\title{
Seismic Fragility Curves for 1 And 2 Stories R/C Buildings
}

\author{
Muhammed Tekin*, Ali Gurbuz ** \\ *Department of Civil Engineering, Faculty of Engineering, Gelisim University, Istanbul \\ ** Department of Civil Engineering, Faculty of Engineering, Recep Tayyip Erdogan University, Rize \\ mtekin@gelisim.edu.tr, ali.gurbuz@erdogan.edu.tr \\ † Corresponding author; Muhammed Tekin, Department of Civil Engineering, Faculty of Engineering, Gelisim University, \\ Istanbul, mtekin@gelisim.edu.tr
}

Received: 20.04.2015 Accepted:23.06.2015

\begin{abstract}
In this study, the fragility curves were formed for 1 and 2 stories reinforced concrete (RC) residential buildings. The information regarding the structures was taken from projects of the buildings. Nonlinear pushover (NP) analyze was performed to $84 \mathrm{RC}$ buildings which were divided to 2 groups. The buildings built 1998 and later were called Group-A. The building built before 1998 was called Group B. As for nonlinear analysis, a 3D computer model was drawn for each building and nonlinear analyses were applied to these models. Each building was analysed for 2 dimensions (X and Y). Totally 168 NP analysis were performed for each building. 4 damage limits (slight, moderate, heavy and complete) and 5 damage zones (undamaged, slight, medium, extensive and collapse) were determined according to maximum interstorey drift ratio. Fragility curve parameters were obtained at the result of the NP analysis. Probability density functions were calculated with the help of lognormal mean and lognormal standard deviation values of limit states. The fragility curves were generalized for the buildings in Group A and Group B. At the conclusion of this work; 8 fragility curves obtained for 1 and 2 stories reinforced concrete buildings in. Using these 8 curves; damage possibility can be estimated for RC buildings which have same features.
\end{abstract}

Keywords Fragility curves, regional earthquake risk, low rise reinforced concrete structures

\section{Introduction}

Seismic evaluation of the existing building stock has become a recognized priority after damage and collapse of many reinforced concrete (RC) structures during recent earthquakes [1]. Turkey is frequently exposed to destructive earthquakes. Besides, it is one of several countries in which earthquakes causing loss of lives occur with the shortest return period [2], [3]. It is known that more than $80 \%$ of the land of the country is under high seismic risk [4].

Considerable heavy damages have happened because of the earthquakes during the last 10 years [5]. RC buildings built before the modern codes have either collapsed or sustained extensive damage during the past earthquakes because of low quality concrete, poor confinement of the end regions of columns and beams, weak column-strong beam behavior, short column behavior, inadequate splice lengths and improper hooks of the stirrups [4], [6], [7]. ].

There are several study about earthquake damages and loss estimation methods for RC buildings. On the other hand, low rise $\mathrm{RC}$ structures are not considered as fragile. Especially one and two-storey buildings are usually ignored. However low rise reinforced concrete (RC) structures are not considered as fragile, there has been several collapse case in recent earthquakes. The paper aims to develop useful damage estimation tools for 1 and 2 stories RC structures.

\section{Earthquake Hazard for Turkey}

Turkey is located on active faults. The country has hazardous earthquake zones. Turkey earthquake zoning map is shown in Figure 1 [8]. Istanbul is the largest city in Turkey, constituting the country's economic, cultural, and historical center. Istanbul is located on the North Anatolian Fault Line. The city and its surrounding areas have been hit by an estimated above 100 earthquakes over the last years according to the Istanbul municipality's disaster coordination center. More than 110,000 deaths, 250,000 hospitalizations and 600,000 destroyed housing units were recorded across turkey as a result of earthquakes in the 20th century [26], [27].

Many earthquakes have been recording every year in the country. Table 1 shows that four and above magnitude earthquakes which were occurred between 30 days in Turkey and its surrounding areas. Likewise; more than 1800 earthquakes were recorded around the country just over the 30 days according to Republic of Turkey, Disaster and Emergency Management Presidency [9]. Table 1 and Figure 2 show that four and above magnitude earthquakes 
occurred between last 30 days (14 March - 15 April 2015) in Turkey and its surrounding areas.

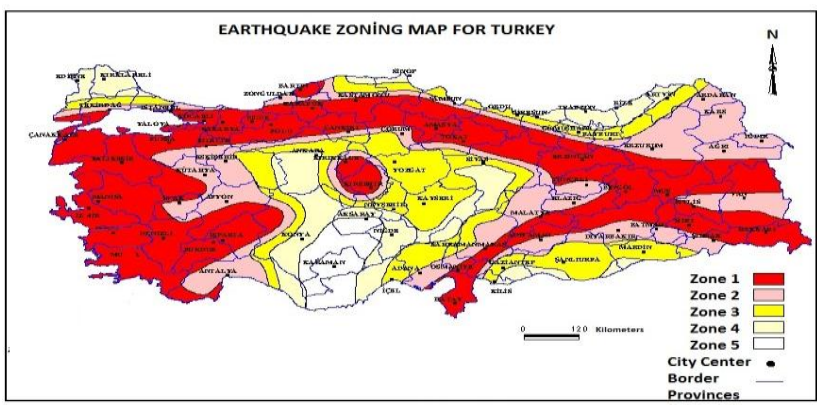

Fig. 1.Earthquake zoning map [8].

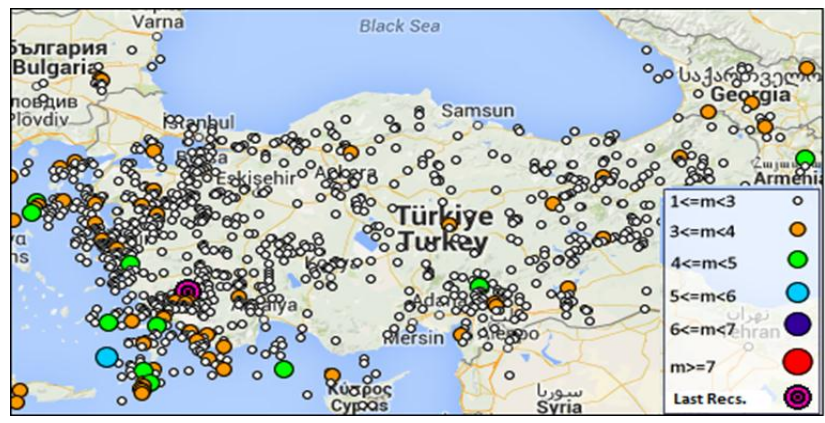

Fig. 2. Earthquake data records for Turkey and its surrounding areas [9].

13 records are shown in table 1 . The biggest magnitude earthquake is 5.0 in the table. It was occurred in Aegean Sea, the latitude of 357.295 and longitude of 265.760 .

Table 1. Four and above magnitude earthquakes occurred between 14 March - 15 April 2015 in Turkey and its surrounding areas [9].

\begin{tabular}{|c|c|c|c|c|c|c|c|}
\hline DATE (GMT) & LATITUDE & LONGITUDE & DEPTH & RMS & MAGNITUDE & & ATION \\
\hline $20 / 06 / 2015$ 19:52:47 & 34.7483 & 26.3781 & 7.33 & 0.77000 & 4.5 & - & AKDENIZ-DOGU BASENI \\
\hline $18 / 06 / 201501: 52: 58$ & 35.0610 & 26.6098 & 20.93 & 0.90000 & 4,1 & . & GIRTT \\
\hline $13 / 06 / 201501: 03: 15$ & 38.6620 & 40.1986 & 25.11 & 0.56000 & 4 & Turkey & BINGÖL \\
\hline $09 / 06 / 201521: 49: 50$ & 35.1771 & 26.8226 & 12.74 & 0.87000 & 5.1 & . & AKDENIZ-DOGU BASEN: \\
\hline $09 / 06 / 201501: 09: 03$ & 38.7675 & 23.4230 & 5.56 & 0.49000 & 5 & Greece & Greece \\
\hline $08 / 06 / 201522: 20: 59$ & 35.3550 & 26.9141 & 38.73 & 0.77000 & 4.4 & ONIKI ADA & ONIKI ADA \\
\hline $03 / 06 / 201509: 35: 41$ & 40.7560 & 49,4020 & 15 & 0.80000 & 4.6 & Azerbajan & Azerbajan \\
\hline $09 / 06 / 201514: 54: 16$ & 37.5080 & 43.8820 & 12.69 & 0.64000 & 4 & Turkey & HAKKARI \\
\hline $30 / 05 / 2015$ 01:56:17 & 40.2100 & 21.7920 & 16.20 & 0.40000 & 4 & Greece & Greece \\
\hline $29 / 05 / 201508: 02: 51$ & 36.8703 & 27.5928 & 17.01 & 0.25000 & 4.1 & GÖKOVA & GOKOVA \\
\hline $29 / 05 / 201500: 03: 48$ & 34.9566 & 26.7278 & 15.85 & 0.82000 & 4.1 & AKDENIZ: & AKDENIZ. \\
\hline $28 / 05 / 201512: 59: 21$ & 35.0620 & 26.7396 & 6.44 & 0.68000 & 4.2 & GIRT & - \\
\hline
\end{tabular}

The loss estimation is based on the damage states of the structures. There are several models which can be used to quantify the damages, characterization of damage state and estimation of losses after the earthquakes [11]. Fragility analysis is one of the key components in seismic risk assessment and more specifically in regional seismic risk assessment [12].

For instance, Federal Emergency Management Agency (FEMA) has developed HAZUS methodology for Estimating Potential Losses from Disasters. HAZUS uses a systematic approach for probabilistic damage assessment of structures [13], [14]. As part of these procedures, fragility curves are employed in order to estimate the damage of a building after various intensities of ground motion shaking [15]. Fragility curves express the probability of the structure reaching or exceeding various damage states as a function of a specific earthquake intensity measure. The function of fragility curves can be assumed as a cumulative distribution function, such as a normal distribution, lognormal distribution or beta distribution [10], [14], [16], [25].

\section{Fragility Curves}

Fragility curve is a useful tool for predicting earthquake risk of buildings with similar characteristics such as material, height and design code level [12]. The curves can be formed using one of three kinds of procedures: (a) the experimental procedure, (b) the nonlinear static analysis based procedure, (c) the dynamic analysis based procedure [17]. The principle of the analytical method which is preferred in this study is to analyze the damage state of structures.

On the other side, fragility curves are cumulative distribution functions that probability of reaching or exceeding a damage state as demand parameters such as story drift ratio (SDR), peak ground acceleration (PGA), spectral acceleration (Sa) or spectral displacement $(\mathrm{Sd})$ [10], [15], [18], [19]. It has been widely accepted that spectral displacement can be closely correlated with seismic damage of structures [18], [19]. Probability density function of a random variable with lognormal distribution is as follows equation-1:

$$
f(x)=\frac{1}{x \sigma_{Y} \sqrt{2 \pi}} \exp -\left[-\frac{\left(\ln x-\mu_{Y}\right)^{2}}{2 \sigma_{Y}^{2}}\right],(0<x<+\infty)
$$

In this distribution; $\mu_{\mathrm{Y}}$ is lognormal mean of variable $\mathrm{Y}$ and $\sigma_{\mathrm{Y}}$ is lognormal standard deviation of variable $\mathrm{Y} . \mu_{\mathrm{X}}$ ve $\sigma_{X}$ are associated with $\mu_{Y}$ ve $\sigma_{Y}$ by equation- 2 and equation-3.

$$
\begin{aligned}
& \mu_{\mathrm{Y}}=\ln \left[\mu_{\mathrm{X}} / \sqrt{\left(\frac{\sigma_{\mathrm{X}}^{2}}{\mu_{\mathrm{X}}^{2}}+1\right)}\right] \\
& \sigma_{\mathrm{Y}}=\sqrt{\ln \left(\frac{\sigma_{\mathrm{X}}^{2}}{\mu_{\mathrm{X}}{ }^{2}}+1\right)}
\end{aligned}
$$

Probability distribution of earthquake damage is assumed to be lognormal distribution. Thus, the analytical expression of fragility curve for a damage level is written as the follows equation-4

$$
P d \geq\left(d_{S_{i}} \mid S_{d}\right)=\varphi\left(\frac{\ln \left(S_{d}\right)-\overline{S_{d_{s_{i}}}}}{\beta_{d_{s_{i}}}}\right)
$$

$\mathrm{Pd}$ is probability of damage. $\mathrm{Sd}$ is modal displacement. $d_{S_{i}}$ is modal displacement for damage level "i". $\overline{\mathrm{S}_{\mathrm{d}_{\mathrm{s}_{\mathrm{i}}}}}$ is mean modal displacement for damage level " $\mathrm{i}$ ". $\beta_{\mathrm{d}_{s_{i}}}$ is lognormal standard deviation of modal displacement values for damage level "i". $\varphi$ is cumulative distribution function. 
In this study, analytical parameters of fragility curves were obtained by nonlinear static pushover (NP) analysis. In the newly developed performance-based seismic design, $\mathrm{NP}$ analysis is one of the useful methods for determining the patterns and levels of damage for assessing a structure's inelastic behavior [20]. NP analysis uses lateral external static forces at floor levels, in combination with inelastic response spectra [21], [22]. Generally, the first mode response of the structures is considered in NP analysis [23]. In case, fundamental mode of vibration is the predominant response of structures [20]. There is a relatively good statistical correlation observed between the earthquake-induced displacement and the extent of structural damage contributed [24, [12]. NP analysis was performed on $3 \mathrm{D}$ computer models of the buildings by CSI SAP2000 computer program.

\section{Building Stock}

1 and 2 stories $84 \mathrm{RC}$ residential buildings discussed within earthquake damage risk. The buildings were selected by random sampling method from municipal archives. Total 84 structures were divided to 2 groups which are Group A and Group B. the buildings built 1998 and later were called Group-A and the building built before 1998 was called Group B. NP analysis was performed to all structures in 2 directions. Parameters of the buildings in Group A and Group B have given in Table 2.

Concrete and reinforcement bar classifications were made according to Turkish Standards TS500 and TS708. A lot of similarities were observed between the buildings built 1998 and later as shown in table 2. Concrete class was usually observed as $\mathrm{C} 16$ and reinforcement bars were usually observed as S420.

As for Group B; concrete class was usually observed as C14 and reinforcement bars were usually observed as S220 for Group A. Column and beam sizes were almost similar with Group A. In addition to table 2 and table 3, the slab thickness are usually $10 \mathrm{~cm}$, story highness of the buildings are observed between 2,60 and 2,80m for both 2 groups. Stirrup diameter was $8 \mathrm{~mm}$ in all columns and beams.

\section{Modeling and Analysis}

In this study; 3D computer models was occurred for buildings to analyze the damage state of structures. As for the modeling issues; columns defined as R/C elements which work for axial load, M2 and M3 moment. Beams also defined as R/C element which working M3 moment. Soil-structure interaction was not considered. All translations and rotations are highlighted for lower ends of the columns at the bottom floor. Otherwise, "Mander model" was used for the stress-strain relation of concrete model (Mander 1988, Ersoy and Ozcebe 2010).

The shear capacity of the section was evaluated based on the code of ATC 32 recommendations. According to ATC -32 , the shear strength of the hoops is determined as:

$$
V_{S}=\frac{A_{s} f_{y} d^{\prime}}{s}
$$

Where As is the cross-sectional area of the transverse reinforcement, $f_{y}$ is the steel yield strength; $d$ ' is effective depth and $s$ is the vertical hoops spacing.

The shear strength provided by the concrete is taken as:

$$
V_{c}=2\left[1+\frac{P_{e}}{2000 A_{g}}\right] \sqrt{f_{c}^{\prime}} A_{e}
$$

Where $\mathrm{P}_{\mathrm{e}}$ is the axial compressive force on the column, Ag is the gross shaft area and Ae is the effective shear area of column.

$3.8 \mathrm{kN} / \mathrm{m}^{2}$ load was assigned to exterior beams due to brick wall but $2.5 \mathrm{kN} / \mathrm{m}^{2}$ assigned on the interior beams. The rigid diaphragm effect was modeled using "joint constrains" properties. Plastic hinges were defined on the both upper and lower ends of columns and beams to idealize the nonlinear behavior. Plastic hinge length was considered as half of cross sections.

Nonlinear pushover analyze was applied for each building in two dimensions. Totally, 120 modal capacity curves were obtained at the result of NP analysis. Figure 4 shows that the highest and the lowest capacity curves as an example.

The building B07 (from group B) has the lowest capacity and the building A12 (form goup A) has the higher capacity as shown in figure 3 . In addition; general performance of the buildings in group $\mathrm{A}$ is higher than the buildings in group B.

After the obtaining modal capacity curves, it was described the damage levels according interstory drift ratio. Table 4 shows that damage levels for low story reinforced concrete frame buildings according to interstory drift ratios.

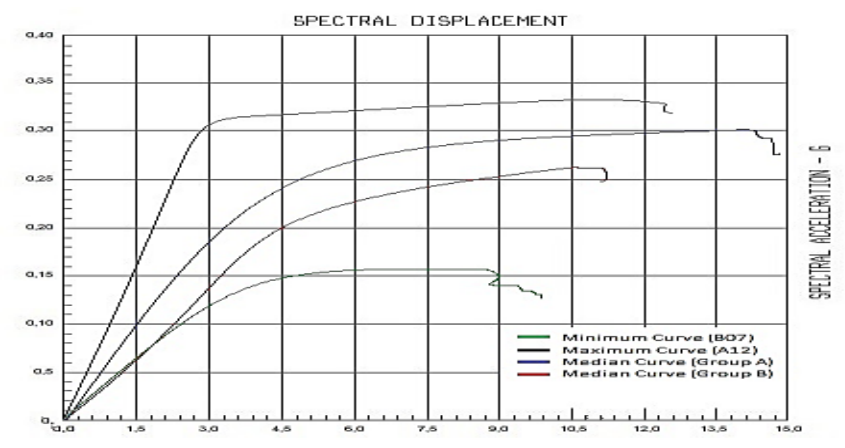

Fig. 3. 3D model and Modal Capacity Curve of Building A01 as an example. 
INTERNATIONAL JOURNAL Of ENGINEERING TECHNOLOGIES

Muhammed Tekin et al., Vol.1, No.2, 2015

Table 2 Building Parameters of Group A.

\begin{tabular}{|c|c|c|c|c|c|c|c|c|c|}
\hline $\begin{array}{l}\text { Building } \\
\text { Code }\end{array}$ & $\begin{array}{c}\text { Project } \\
\text { Year }\end{array}$ & $\begin{array}{l}\text { Number } \\
\text { of Story }\end{array}$ & $\begin{array}{c}\text { Majority } \\
\text { Column } \\
\text { Size }(\mathrm{cm})\end{array}$ & $\begin{array}{l}\text { Majority } \\
\text { Beam } \\
\text { Size }(\mathrm{cm})\end{array}$ & $\begin{array}{l}\text { Concrete } \\
\text { Material }\end{array}$ & $\begin{array}{l}\text { Bar } \\
\text { Mat. }\end{array}$ & $\begin{array}{c}\text { Soil } \\
\text { Type }\end{array}$ & $\begin{array}{c}\text { Plan } \\
\text { Irregularity }\end{array}$ & $\begin{array}{c}\text { Short } \\
\text { Column }\end{array}$ \\
\hline $\mathrm{A} 01$ & 2004 & 1 & $25 \times 40$ & $25 \times 50$ & C16 & S420 & $\mathrm{Z2}$ & No & No \\
\hline A02 & 2005 & 1 & $30 \times 50$ & $25 \times 50$ & C16 & S420 & $\mathrm{Z3}$ & No & No \\
\hline A03 & 2008 & 1 & $30 \times 50$ & $25 \times 50$ & C16 & S420 & Z3 & No & No \\
\hline A04 & 2008 & 1 & $40 \times 40$ & $30 \times 50$ & $\mathrm{C} 14$ & S220 & $\mathrm{Z3}$ & No & No \\
\hline A05 & 1998 & 1 & $25 \times 40$ & $25 \times 50$ & C16 & S420 & $\mathrm{Z} 4$ & No & No \\
\hline A06 & 1998 & 1 & $30 \times 30$ & $30 \times 50$ & $\mathrm{C} 16$ & S220 & Z3 & No & No \\
\hline A07 & 1998 & 1 & $30 \times 40$ & $30 \times 60$ & $\mathrm{C} 20$ & S420 & Z3 & No & $\mathrm{No}$ \\
\hline A08 & 1999 & 1 & $25 \times 40$ & $30 \times 50$ & C16 & S420 & $\mathrm{Z} 2$ & Yes & No \\
\hline A09 & 1999 & 1 & $30 \times 30$ & $30 \times 50$ & $\mathrm{C} 20$ & S420 & Z3 & No & No \\
\hline A10 & 1999 & 1 & $30 \times 40$ & $30 \times 50$ & C16 & S420 & $\mathrm{Z3}$ & No & No \\
\hline A11 & 1999 & 1 & $25 \times 40$ & $25 \times 50$ & $\mathrm{C} 20$ & S220 & $\mathrm{Z4}$ & No & No \\
\hline A12 & 1999 & 1 & $30 \times 50$ & $30 \times 50$ & C16 & S220 & Z3 & No & No \\
\hline A13 & 1999 & 1 & $30 \times 50$ & $30 \times 50$ & $\mathrm{C} 20$ & S420 & $\mathrm{Z} 4$ & Yes & No \\
\hline A14 & 2000 & 1 & $25 \times 40$ & $25 \times 50$ & C16 & S420 & Z3 & No & No \\
\hline A15 & 2000 & 1 & $30 \times 40$ & $30 \times 50$ & C16 & S420 & $\mathrm{Z} 4$ & No & No \\
\hline A16 & 2001 & 2 & $25 \times 50$ & $25 \times 50$ & C16 & S420 & $\mathrm{Z4}$ & No & No \\
\hline A17 & 2001 & 2 & $30 \times 30$ & $25 \times 50$ & C16 & S420 & $\mathrm{Z3}$ & No & $\mathrm{No}$ \\
\hline A18 & 2001 & 2 & $30 \times 50$ & $25 \times 50$ & C16 & S420 & $\mathrm{Z} 2$ & No & No \\
\hline A19 & 2001 & 2 & $30 \times 30$ & $25 \times 50$ & $\mathrm{C} 20$ & S420 & $\mathrm{Z3}$ & No & No \\
\hline A20 & 2002 & 2 & $25 \times 40$ & $30 \times 50$ & $\mathrm{C} 16$ & S420 & $\mathrm{Z3}$ & No & No \\
\hline A21 & 2002 & 2 & $30 \times 40$ & $25 \times 50$ & C16 & S420 & Z3 & No & No \\
\hline A22 & 2002 & 2 & $30 \times 40$ & $30 \times 50$ & C16 & S420 & $\mathrm{Z3}$ & No & No \\
\hline A23 & 2003 & 2 & $25 \times 40$ & $30 \times 50$ & C16 & S420 & $\mathrm{Z3}$ & No & Yes \\
\hline A24 & 2003 & 2 & $30 \times 30$ & $25 \times 50$ & C16 & S420 & $\mathrm{Z3}$ & Yes & No \\
\hline A25 & 2003 & 2 & $40 \times 40$ & $30 \times 50$ & $\mathrm{C} 16$ & S420 & $\mathrm{Z2}$ & Yes & No \\
\hline A26 & 2003 & 2 & $30 \times 30$ & $30 \times 50$ & C16 & S420 & $\overline{Z 3}$ & No & $\mathrm{No}$ \\
\hline A27 & 2003 & 2 & $25 \times 40$ & $25 \times 50$ & C16 & S420 & $\mathrm{Z2}$ & No & No \\
\hline A28 & 2003 & 2 & $25 \times 40$ & $25 \times 50$ & $\mathrm{C} 18$ & S420 & $\mathrm{Z3}$ & $\mathrm{No}$ & No \\
\hline A29 & 2003 & 2 & $30 \times 40$ & $30 \times 50$ & $\mathrm{C} 16$ & S420 & $\mathrm{Z} 4$ & No & No \\
\hline A30 & 2003 & 2 & $30 \times 30$ & $25 \times 50$ & $\mathrm{C} 14$ & S420 & $\mathrm{Z3}$ & No & No \\
\hline A31 & 2003 & 2 & $40 \times 40$ & $25 \times 50$ & C16 & S420 & $\mathrm{Z3}$ & No & No \\
\hline A32 & 2004 & 2 & $25 \times 40$ & $30 \times 60$ & C16 & S420 & $\mathrm{Z3}$ & No & No \\
\hline A33 & 2004 & 2 & $40 \times 40$ & $25 \times 50$ & C16 & S420 & $\mathrm{Z3}$ & No & No \\
\hline A34 & 2004 & 2 & $25 \times 40$ & $25 \times 50$ & $\mathrm{C} 20$ & S420 & $\mathrm{Z} 2$ & No & No \\
\hline A35 & 2004 & 2 & $25 \times 40$ & $30 \times 60$ & C16 & S420 & $\mathrm{Z} 2$ & No & Yes \\
\hline A36 & 2004 & 2 & $30 \times 30$ & $25 \times 50$ & $\mathrm{C} 16$ & S420 & $\mathrm{Z3}$ & No & Yes \\
\hline A37 & 2004 & 2 & $30 \times 30$ & $30 \times 50$ & C16 & S420 & $\mathrm{Z4}$ & No & No \\
\hline A38 & 2005 & 2 & $40 \times 40$ & $25 \times 50$ & C16 & S420 & Z3 & $\mathrm{No}$ & $\mathrm{No}$ \\
\hline A39 & 2005 & 2 & $25 \times 40$ & $30 \times 50$ & $\mathrm{C} 16$ & S420 & $\mathrm{Z} 4$ & Yes & No \\
\hline A40 & 2005 & 2 & $25 \times 40$ & $25 \times 50$ & $\mathrm{C} 20$ & S420 & $\mathrm{Z} 4$ & No & No \\
\hline A41 & 2006 & 2 & $40 \times 40$ & $30 \times 60$ & $\mathrm{C} 20$ & S420 & $\mathrm{Z3}$ & Yes & No \\
\hline A42 & 2006 & 2 & $30 \times 30$ & $30 \times 50$ & C20 & S420 & $\mathrm{Z3}$ & Yes & No \\
\hline A43 & 2006 & 2 & $25 \times 30$ & $30 \times 60$ & $\mathrm{C} 20$ & S420 & $\mathrm{Z4}$ & No & No \\
\hline A44 & 2006 & 2 & $25 \times 40$ & $25 \times 50$ & $\mathrm{C} 20$ & S420 & Z3 & No & No \\
\hline A45 & 2007 & 2 & $40 \times 40$ & $30 \times 60$ & $\mathrm{C} 20$ & S420 & $\mathrm{Z} 2$ & No & No \\
\hline A46 & 2008 & 2 & $30 \times 30$ & $30 \times 50$ & $\mathrm{C} 20$ & S420 & $\mathrm{Z3}$ & No & No \\
\hline A47 & 2008 & 2 & $25 \times 30$ & $25 \times 50$ & $\mathrm{C} 20$ & S420 & $\mathrm{Z3}$ & No & Yes \\
\hline A48 & 2008 & 2 & $25 \times 40$ & $30 \times 50$ & $\mathrm{C} 20$ & S420 & $\mathrm{Z3}$ & Yes & No \\
\hline A49 & 2008 & 2 & $25 \times 30$ & $25 \times 50$ & $\mathrm{C} 20$ & S420 & $\mathrm{Z2}$ & No & No \\
\hline A50 & 2008 & 2 & $25 \times 30$ & $25 \times 50$ & $\mathrm{C} 20$ & S420 & $\mathrm{Z2}$ & No & No \\
\hline A51 & 2008 & 2 & $30 \times 30$ & $25 \times 50$ & $\mathrm{C} 20$ & S420 & $\mathrm{Z3}$ & No & No \\
\hline A52 & 2009 & 2 & $40 \times 40$ & $30 \times 60$ & $\mathrm{C} 20$ & S420 & $\mathrm{Z} 4$ & No & No \\
\hline A53 & 2009 & 2 & $25 \times 40$ & $25 \times 50$ & $\mathrm{C} 20$ & S420 & $\mathrm{Z4}$ & No & No \\
\hline A54 & 2009 & 2 & $25 \times 40$ & $30 \times 50$ & $\mathrm{C} 20$ & S420 & Z3 & No & No \\
\hline A55 & 2009 & 2 & $30 \times 30$ & $25 \times 50$ & $\mathrm{C} 20$ & S420 & $\mathrm{Z} 3$ & No & No \\
\hline A56 & 2009 & 2 & $25 \times 40$ & $30 \times 50$ & $\mathrm{C} 20$ & S420 & $\mathrm{Z3}$ & No & No \\
\hline A57 & 2009 & 2 & $25 \times 40$ & $25 \times 50$ & $\mathrm{C} 20$ & S420 & $\mathrm{Z2}$ & No & No \\
\hline A58 & 2009 & 2 & $25 \times 40$ & $30 \times 60$ & $\mathrm{C} 20$ & S420 & Z3 & No & $\mathrm{No}$ \\
\hline A59 & 2010 & 2 & $30 \times 30$ & $30 \times 50$ & $\mathrm{C} 20$ & S420 & $\mathrm{Z4}$ & No & No \\
\hline
\end{tabular}


INTERNATIONAL JOURNAL Of ENGINEERING TECHNOLOGIES

Muhammed Tekin et al., Vol.1, No.2, 2015

\begin{tabular}{|l|l|l|l|l|l|l|l|l|l|}
\hline A60 & 2010 & 2 & $40 \times 40$ & $25 \times 50$ & C20 & S420 & Z3 & Yes & No \\
\hline A61 & 2010 & 2 & $25 \times 40$ & $30 \times 60$ & C20 & S420 & Z3 & No & No \\
\hline A62 & 2010 & 2 & $25 \times 40$ & $30 \times 50$ & C20 & S420 & Z4 & No & No \\
\hline A63 & 2011 & 2 & $30 \times 30$ & $25 \times 50$ & C20 & S420 & Z3 & No & No \\
\hline
\end{tabular}

Table 3 Building Parameters of Group B.

\begin{tabular}{|c|c|c|c|c|c|c|c|c|c|}
\hline $\begin{array}{c}\text { Building } \\
\text { Code }\end{array}$ & $\begin{array}{c}\text { Project } \\
\text { Year }\end{array}$ & $\begin{array}{l}\text { Number } \\
\text { of Story }\end{array}$ & $\begin{array}{c}\text { Majority } \\
\text { Column } \\
\text { Size }(\mathbf{c m})\end{array}$ & $\begin{array}{l}\text { Majority } \\
\text { Beam } \\
\text { Size }(\mathrm{cm})\end{array}$ & $\begin{array}{l}\text { Concrete } \\
\text { Material }\end{array}$ & $\begin{array}{l}\text { Bar } \\
\text { Mat. }\end{array}$ & $\begin{array}{c}\text { Soil } \\
\text { Type }\end{array}$ & $\begin{array}{c}\text { Plan } \\
\text { Irregularity }\end{array}$ & $\begin{array}{c}\text { Short } \\
\text { Column }\end{array}$ \\
\hline B01 & 1973 & 2 & $30 \times 30$ & $25 \times 50$ & $\mathrm{C} 16$ & S220 & $\mathrm{Z} 2$ & Yes & No \\
\hline B02 & 1974 & 2 & $25 \times 40$ & $25 \times 50$ & $\mathrm{C} 16$ & S220 & $\mathrm{Z3}$ & No & No \\
\hline B03 & 1977 & 2 & $30 \times 30$ & $25 \times 50$ & C16 & S220 & $\mathrm{Z3}$ & No & No \\
\hline B04 & 1978 & 2 & $40 x 40$ & $30 \times 50$ & $\mathrm{C} 16$ & S220 & $\mathrm{Z3}$ & No & No \\
\hline B05 & 1984 & 1 & $25 \times 40$ & $25 \times 50$ & $\mathrm{C} 14$ & S220 & $\mathrm{Z3}$ & No & No \\
\hline B06 & 1985 & 2 & $30 \times 30$ & $25 \times 50$ & $\mathrm{C} 14$ & S220 & $\mathrm{Z3}$ & No & Yes \\
\hline B07 & 1986 & 1 & $25 \times 40$ & $30 \times 60$ & $\mathrm{C} 14$ & S220 & $\mathrm{Z4}$ & Yes & Yes \\
\hline B08 & 1986 & 2 & $25 \times 40$ & $25 \times 50$ & $\mathrm{C} 14$ & S220 & $\mathrm{Z3}$ & No & No \\
\hline B09 & 1987 & 2 & $25 \times 40$ & $25 \times 50$ & $\mathrm{C} 16$ & S220 & $\mathrm{Z3}$ & No & No \\
\hline B10 & 1988 & 2 & $30 \times 30$ & $25 \times 50$ & C16 & S220 & $\mathrm{Z3}$ & No & No \\
\hline B11 & 1989 & 2 & $25 \times 40$ & $25 \times 50$ & C16 & S220 & $\mathrm{Z} 2$ & No & No \\
\hline B12 & 1989 & 2 & $30 \times 50$ & $25 \times 50$ & C16 & S220 & $\mathrm{Z3}$ & No & No \\
\hline B13 & 1993 & 2 & $25 \times 40$ & $25 \times 50$ & $\mathrm{C} 14$ & S220 & $\mathrm{Z3}$ & Yes & No \\
\hline B14 & 1995 & 2 & $30 \times 30$ & $25 \times 50$ & $\mathrm{C} 16$ & S420 & $\mathrm{Z3}$ & No & No \\
\hline B15 & 1995 & 2 & $25 \times 40$ & $30 \times 50$ & $\mathrm{C} 16$ & S220 & $\mathrm{Z3}$ & No & No \\
\hline B16 & 1996 & 1 & $30 \times 50$ & $30 \times 60$ & $\mathrm{C} 14$ & S220 & $\mathrm{Z} 4$ & No & No \\
\hline B17 & 1996 & 2 & $25 \times 40$ & $25 \times 50$ & $\mathrm{C} 16$ & S220 & $\mathrm{Z} 2$ & No & No \\
\hline B18 & 1997 & 1 & $30 \times 30$ & $25 \times 50$ & $\mathrm{C} 20$ & S420 & $\mathrm{Z4}$ & No & Yes \\
\hline B19 & 1997 & 1 & $30 \times 50$ & $25 \times 50$ & $\mathrm{C} 16$ & S220 & $\mathrm{Z3}$ & Yes & No \\
\hline B20 & 1997 & 2 & $30 \times 40$ & $25 \times 50$ & $\mathrm{C} 16$ & S220 & $\mathrm{Z3}$ & No & No \\
\hline B21 & 1997 & 2 & $25 \times 50$ & $25 \times 50$ & $\mathrm{C} 20$ & S420 & $\mathrm{Z} 2$ & No & No \\
\hline
\end{tabular}

Table 4. Damage levels according to FEMA HAZUS MH MR 5.

\begin{tabular}{|l|l|l|l|l|}
\hline $\begin{array}{l}\text { Design } \\
\text { Code }\end{array}$ & $\begin{array}{l}\text { Slight } \\
\text { Damage } \\
(\boldsymbol{\%})\end{array}$ & $\begin{array}{l}\text { Medium } \\
\text { Damage } \\
(\boldsymbol{\%})\end{array}$ & $\begin{array}{l}\text { Heavy } \\
\text { Damage } \\
(\boldsymbol{\%})\end{array}$ & $\begin{array}{l}\text { Collapse } \\
(\boldsymbol{\%})\end{array}$ \\
\hline $\begin{array}{l}\text { Low } \\
\text { Code }\end{array}$ & 0,005 & 0,008 & 0,02 & 0,05 \\
\hline $\begin{array}{l}\text { Moderate } \\
\text { Code }\end{array}$ & 0,005 & 0,0087 & 0,0233 & 0,06 \\
\hline
\end{tabular}

The buildings in Group A were assumed as "moderate code" and the buildings in Group B "were assumed as "low code" in the table.

At the final step of calculations; lognormal mean modal displacement and lognormal standard deviation of modal displacement values were utilized as parameters of fragility curves. All parameters of fragility curves are shown in table 5 for Group A and Group B.
Table 5. Parameters of Fragility Curves.

\begin{tabular}{|c|c|c|c|c|c|c|c|c|}
\hline Groups & \multicolumn{2}{|c|}{$\begin{array}{c}\text { Sd1 } \\
\text { (Slight) }\end{array}$} & \multicolumn{2}{c|}{$\begin{array}{c}\text { Sd2 } \\
\text { (Moderate) }\end{array}$} & \multicolumn{2}{|c|}{$\begin{array}{c}\text { Sd3 } \\
\text { (Heavy) }\end{array}$} & \multicolumn{2}{|c|}{$\begin{array}{c}\text { Sd4 } \\
\text { (Collapse) }\end{array}$} \\
\cline { 2 - 9 } & LM & LS & LM & LS & LM & LS & LM & LS \\
\hline A & 1,09 & 0,32 & 1,66 & 0,39 & 2,24 & 0,39 & 2,94 & 0,39 \\
\hline B & 0,83 & 0,37 & 1,30 & 0,39 & 2,31 & 0,46 & 3,08 & 0,40 \\
\hline
\end{tabular}

4 fragility curves were calculated for each group using the parameters in table 5. Figure 5 and Figure 6 show the fragility curves of slight, moderate, heavy and complete damage level for Group A and Group B.

In the literature; the best value for the damage estimation is 50 percent corresponding to the mid-point of fragility curve. Then the Group A buildings would be situated in undamaged zone with more than $\% 50$ probabilities for $3 \mathrm{~cm}$ modal displacement. Similarly, there is more than $\% 50$ probabilities for the buildings to be situated in slight damage zone between 3 and $5,30 \mathrm{~cm}$. There is $\% 51$ possibility to be in moderate damage zone between 5,30 and $13 \mathrm{~cm}$ spectral displacement. As for 
heavy damage zone, this value changed between $13 \mathrm{~cm}$ and $19 \mathrm{~cm}$. Finally, the buildings have more than $\% 50$ possibilities being in collapse zone for above $19 \mathrm{~cm}$ spectral displacement value.

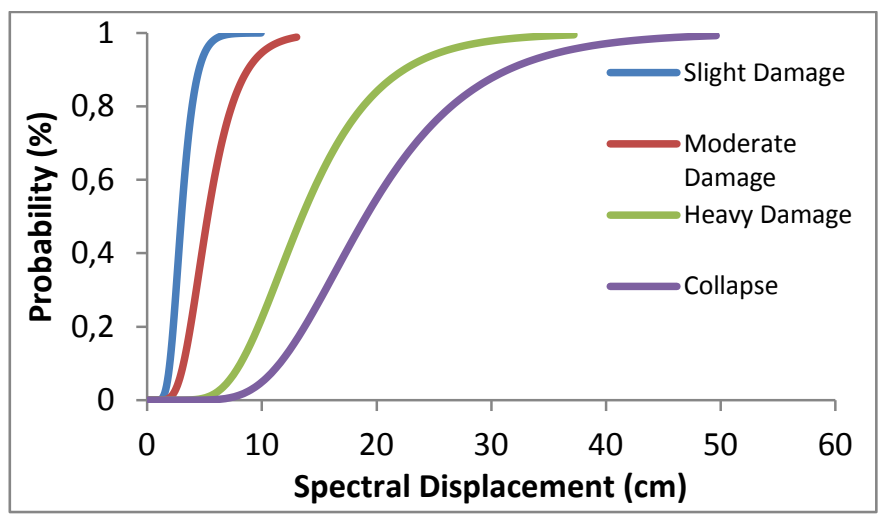

Fig. 4. Fragility curves for Group A.

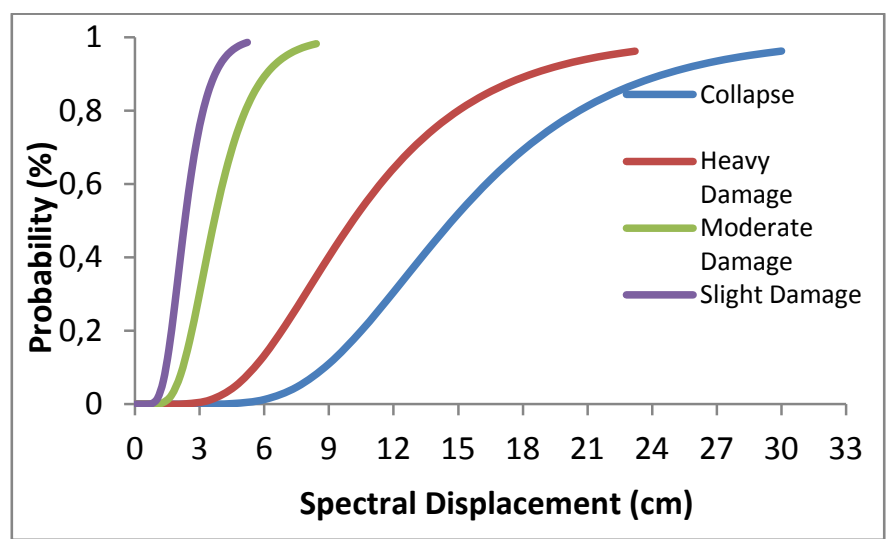

Fig.5. Fragility curves for Group B.

The Group B buildings would be situated in undamaged zone with more than $\% 50$ probabilities for $2,30 \mathrm{~cm}$ modal displacement. Then, there is more than $\% 50$ probabilities for the buildings to be situated in slight damage zone between 2,30 and $3,65 \mathrm{~cm}$. There is $\% 51$ possibility to be in moderate damage zone between 3,65 and $10 \mathrm{~cm}$ spectral displacement. As for extensive damage zone, these values changed between $10 \mathrm{~cm}$ and $15 \mathrm{~cm}$. Finally, the buildings have more than $\% 50$ possibilities being in collapse zone for above $15 \mathrm{~cm}$ spectral displacement value.

\section{Conclusions}

This paper aims at using numerical simulation to develop fragility curves for 1 and 2 stories RC frame structures. Fragility curves were formed for $84 \mathrm{RC}$ residential buildings. The buildings were divided into 2 groups according to year of Turkish Earthquake Code 1998. A 3D computer model was drawn for each building and analysis was applied to these models. 4 damage limits (slight, moderate, extensive and complete) and 5 damage zones (undamaged, slight, medium, heavy and collapse) were determined according to interstory drift ratios of the buildings. Cumulative probability functions were calculated with the help of lognormal mean and lognormal standard deviation values of limit states. Then, fragility curves that show probability of the damages were generalized.

According to pushover results; the buildings in Group $\mathrm{B}$ have lower lateral capacity compared to the buildings in Group A. However modal capacity curves give information about the current status of the buildings, analyses need long time. Therefore, regional studies and rapid risk assessment methods are required. Therewith, a general assessment can be made by the results of the fragility curves.

In this study, it has been observed that fragility curves were close to each other for slight and moderate levels. The Group A buildings would be situated in undamaged zone with more than $\% 50$ probabilities in the range of 0 $3 \mathrm{~cm}$ modal displacement. Similarly, there is more than $\% 50$ probabilities for the Group A buildings to be situated in slight damage zone in the range of $3,00-5,30 \mathrm{~cm}$, moderate damage zone in the range of $5,30-13 \mathrm{~cm}$, heavy damage zone in the range of $13-19 \mathrm{~cm}$ and collapse zone above $19 \mathrm{~cm}$.

Likewise, The Group B group buildings would be situated in undamaged zone with more than $\% \quad 50$ probabilities in the range of $0-2,30 \mathrm{~cm}$ modal displacement. There is more than $\% 50$ probabilities for the Group B buildings to be situated in slight damage zone in the range of $2,30-3,65 \mathrm{~cm}$, moderate damage zone in the range of $3,65-10 \mathrm{~cm}$, extensive damage zone in the range of 20 $15 \mathrm{~cm}$ and collapse zone above $15 \mathrm{~cm}$.

In conclusion; the buildings in Group A have more ductile behavior as compared to Group B. The difference between fragility curves of Group A and Group B was compared for midpoint of the curves. The buildings in Group A have higher displacement capacity than the buildings in Group B. The difference is approximately $\% 30$ for slight, heavy and collapse damage states. Nevertheless, the difference is increased to approximately $\% 45$ for moderate damage state.

\section{References}

[1] Thermou, Georgia E., Pantazopoulou, Stavroula J., Elnashai, Amr S. "Design Methodology for Seismic Upgrading of Substandard Reinforced Concrete Structures." Journal of Earthquake Engineering, 11 (4), 582-606. 2007. DOI: 10.1080/13632460601031573.

[2] Doğangün, A., "Performance of reinforced concrete buildings during the May 1, 2003 Bingöl Earthquake in Turkey." Engineering Structures, 26 (6), 841-856. 2004. DOI: 10.1016/j.engstruct.2004.02.005

[3] Yilmaz, S., Tama, Y. S., Bilgin, H., "Seismic performance evaluation of unreinforced masonry school buildings in Turkey." Journal of Vibration and Control, 19 (16), 2421-2433. 2012. DOI: 10.1177/1077546312453190

[4] Kaplan, H., Yilmaz, S., Binici, H., Yazar, E., Çetinkaya, N., "May 1, 2003 Turkey-Bingöl earthquake: damage in reinforced concrete structures." Engineering Failure Analysis, 11 (3), 279-291. 2004. DOI: 10.1016/j 
[5] Kaltakci, M, Y., Arslan, M. H., Yilmaz, U. S., Arslan, U. S., "A new approach on the strengthening of primary school buildings in Turkey: An application of external shear wall." Building and Environment, 43 (6), 983-990. 2008. DOI: 10.1016/j.buildenv.2007.02.009

[6] Erdik, M., Şeşetyan, K., Demircioğlu, M. B., Hancılar, U., Zülfikar, C., "Rapid earthquake loss assessment after damaging earthquakes" Soil Dynamics and Earthquake Engineering, 31 (2), 247-266. 2011. DOI: 10.1016/j.soildyn.2010.03.009

[7] Görgülü, T., Tama, Y., S., Yilmaz, S., Kaplan, H., Ay, $Z$., "Strengthening of reinforced concrete structures with external steel shear walls" Journal of Constructional Steel Research, 70, 2012. DOI: 10.1016/j.jcsr.2011.08.010

[8] Özmen, B., Nurlu, M., Güler, H., "Examination of the earthquake zone with geographic information system" in The Ministry of Public Works and Settlement Headquarter of Disaster, pp:9. 1997. URL:deprem.gazi.edu.tr/posts/download?id=43390

[9] Republic of Turkey, Disaster and Emergency Management Presidency, "Earthquake Database", 2015.URL:http://www.deprem.gov.tr/sarbis/Shared/Defaul t.aspx

[10] Hsieh, M.H., Lee, B. J., Lei, T. C., Lin, J. Y., "Development of medium and low-rise reinforced concrete building fragility curves based on Chi-Chi Earthquake data." Natural Hazards, 69 (1), 695-728. 2013. DOI: 10.1007/s11069-013-0733-8

[11] Hamid, N. H. A., Mohamad, N. M., "Seismic Assessment of a Full-Scale Double-Storey Residential House using Fragility Curve." Procedia Engineering, 54, pp: 207-221. 2013. DOI: 10.1016/j.proeng.2013.03.019

[12] Abo-El-Ezz, A., Nollet, M. J., Nastev, M. "Seismic fragility assessment of low-rise stone masonry buildings." Earthquake Engineering and Engineering Vibration, 12(1), 87-97. 2013. DOI: 10.1007/s11803-013-0154-4

[13] HAZUS, "Earthquake Loss Estimation Methodology." HAZUS Technical Report Federal Emergency Agency and National Institute 4(4). Updated 2014.

[14] Park, J., Towashiraporn, P., Craig, J. I., Goodno, B. J. "Seismic fragility analysis of low-rise unreinforced masonry structures." Engineering Structures, 31(1), 125137. 2009. DOI: 10.1016/j.engstruct.2008.07.021

[15] Lignos, D. G., Karamanci, E. "Drift-based and dualparameter fragility curves for concentrically braced frames in seismic regions." Journal of Constructional Steel Research, 90, 209-220. 2013. DOI: 10.1016/j.engstruct.2008.07.021

[16] Bessason, B., Bjarnason, J. Ö., Gudmundsson, A., Sólnes, J., Steedman, S. "Probabilistic Earthquake Damage Curves for Low-Rise Buildings Based on Field Data." Earthquake Spectra, 28 (4), 1353-1378. 2012. DOI: $10.1193 / 1.4000082$
[17] Wu, D., Tesfamariam, S., Stiemer, S. F., and Qin, D. "Seismic fragility assessment of RC frame structure designed according to modern Chinese code for seismic design of buildings." Earthquake Engineering and Engineering Vibration, 11 (3), 331-342. 2012. DOI: 10.1007/s11803-012-0125-1

[18] Su, R. K. L. and Lee, C. L. "Development of seismic fragility curves for low-rise masonry infilled reinforced concrete buildings by a coefficient-based method." Earthquake Engineering and Engineering Vibration, 12 (2), 319-332. 2013. DOI: 10.1007/s11803-013-0174-0

[19] Kircil, M. S., Polat, Z. "Fragility analysis of mid-rise R/C frame buildings." Engineering Structures, 28 (9), 1335-1345. 2006. DOI: 10.1016/j.engstruct.2006.01.004

[20] Zou, X. K., Chan, C. M. "Optimal seismic performance-based design of reinforced concrete buildings using nonlinear pushover analysis." Engineering Structures, 27 (8), 1289-1302. 2005. DOI: 10.1016/j.engstruct.2005.04.001

[21] Makarios, T. K. "Optimum definition of equivalent non-linear SDF system in pushover procedure of multistory r/c frames." Engineering Structures, 27 (5), 814-825. 2005. DOI: 10.1016/j.engstruct.2005.01.005

[22] Belletti, B., Damoni, C., Gasperi, A. "Modeling approaches suitable for pushover analyses of RC structural wall buildings." Engineering Structures, 57, 327-338. 2013. DOI: 10.1016/j.engstruct.2013.09.023

[23] Chopra, A. K., Goel, R. K., Chintanapakdee, C., "Evaluation of a Modified MPA Procedure Assuming Higher Modes as Elastic to Estimate Seismic Demands." Earthquake Spectra, 20 (3), 757-778. 2004. DOI: http://dx.doi.org/10.1193/1.1775237

[24] García, R. J., Negrete, M., "Drift-based fragility assessment of confined masonry walls in seismic zones." Engineering Structures, 31 (1), 170-181. 2009. DOI: 10.1016/j.engstruct.2008.08.010

[25] Bessason, B., J. Ö. Bjarnason, A. Gudmundsson, J. Sólnes and S. Steedman (2012). "Probabilistic Earthquake Damage Curves for Low-Rise Buildings Based on Field Data." Earthquake Spectra 28(4): 1353-1378.

[26] Kestler-D’Amours, J. “Turkey Braces for Next Major Earthquake." Al Jazeera, News (Middleeast). (19 Apr 2014).

URL: http://www.aljazeera.com/news/middleeast/2014/03/turkey -braces-next-major-earthquake-

201431182932518813.html

[27] Istanbul Buyukşehir Belediyesi, "Deprem Master Plan for Istanbul.” Planlama ve Imar Mudurlugu. (2003). 